\title{
FAULT TOLERANT CONTROL OF WIND TURBINE VIA IDENTIFIED FUZZY MODELS PROTOTYPES
}

\author{
Habib Chaouki Ben DJOUDI ${ }^{1}$, Ahmed HAFAIFA ${ }^{1,2}$, Dalila DJOUDI ${ }^{1}$, Mouloud GUEMANA ${ }^{2}$ \\ ${ }^{1}$ Applied Automation and Industrial Diagnostics Laboratory, University of Djelfa, Algeria \\ ${ }^{2}$ Faculty of Technology, University of Médéa, 26000 DZ, Algeria \\ E-mail: hcb.djoudi@univ-djelfa.dz, a.hafaifa@univ-djelfa.dz, d.djoudi@univ-djelfa.dz, \\ guemana.mouloud@univ-medea.dz
}

\begin{abstract}
The main purpose of this study is the comparison of two control strategies of wind turbine $4.8 \mathrm{MW}$, using fuzzy control and proportional integral control, taking into account eight kinds of faults that can occur in a wind turbine model. A technique based on fault diagnosis has been used to detect and isolate faults actuators and sensors in this system, it's about an observer applied to the benchmark model. The obtained results are presented to validate the effectiveness of this diagnostic method and present the results of the proposed control strategies.
\end{abstract}

Keywords: Fault Detection, fault isolation, fault tolerant control, Benchmark model, proportional integral control, fuzzy control.

\section{INTRODUCTION}

The wind energy is strongly involved in electric energy production in the industrial world, like all industrial systems, the wind turbine can be threatened by anomalies which are likely to cause damage to its performance or even cause a complete shutdown of the facility, the methods of faults diagnosis are needed. A fault-tolerant control system (FTC) is characterized by its aptitude to support or to find degraded performances in functioning close to those that it has in normal functioning. Any FTC system must be accompanied by a fault detection and isolation (FDI) system, to design the control laws necessary for such a failure. To enable researchers to test fault-tolerant diagnostic and control approaches applied to a wind system. The Benchmark model has been developed in $[5,8,25,27]$.

The effectiveness of the proposed active fault tolerant control strategy is assessed on data sequences acquired from the considered benchmark (Odgaard et al. in [22], concerning both the fault tolerance tracking capabilities.

At IFAC (International Federation of Automatic Control) World Congress two invited sessions were formed with different solutions proposed for the FDI part of the mentioned benchmark model. In this paper, some of these proposed methods are compared both on test sequences defined in the benchmark and in addition to some additional test sets for testing robust of the proposed schemes to operational point of occurrence of the faults. The compared solutions can be seen in Laouti et al.
[19], Ozdemir et al [1] and in Hamed Badihi et al. in [12]. Results from the FTC port of the previous benchmark can be found in other industrial applications, a set value based observer method was proposed in [3, 9-10] given a control allocation method for FTC of the pitch actuators. A virtual sensor and the actuator scheme were applied in [29]. Fuzzy logic based methods for FTC for operation below rated wind speed were presented in [6-7, 16-17, 23]. Many other solutions have also been applied to this benchmark model, Ayoub EL Bakri et al. in [5], Carl Svärd et al. in [8], Silvio Simani and Paolo Castaldi in [25] and Viveiros C. et al. in [27] . This approach is very interesting seen from an industrial point of view since it does not require modification of the existing nominal controller.

This solution is an active FTC approach. The second contribution uses a Takagi-Sugeno multimodel approach to deal with the nonlinear nature of the wind turbine faults are dealt with by estimating the faults.

This solution can be considered as an active fault-tolerant approach. The last contribution uses adaptive control to deal with the faults. This solution is placed in the category of active/passive combination methods. It can, consequently, be dangerous seen from a practical point-of-view since this strategy might accommodate faults in a wrong way by adaptation, for example, in case of a critical fault, which requires a safety stop. These solutions will first be shortly introduced before they are evaluated and compared on the wind turbine FDI and FTC benchmark model $[5,8,25]$. 
The work is organized as follows. Section second recalls the wind park simulator. Section third we present an FTC architecture that allows reconfiguring the control law for the defects of the benchmark model based on the fuzzy logic control. The achieved results are reported in Section last. Finally, Section concludes the paper by summarising the main achievements of the work and providing some suggestions for further research topics.

\section{WIND TURBINE BASED ON BENCHMARK MODEL}

The Benchmark model used in our work is composed of three blades, variable speeds, horizontal axis wind turbine, shown in Figure 1, with a full-power converter of $4.8 \mathrm{MW}[2,4,21]$. The corresponding block diagram is presented in Figure 2, the wind speed, it goes into the blade and pitch system. Each of the three-pitch positions ( $\mathrm{i}=1$, 2,3 ) is measured with two sensors for physical redundancy requirements. They are defined as $\beta_{1, m 1}, \beta_{1, m 2}, \beta_{2, m 1}, \beta_{2, m 2}, \beta_{3, m 1}, \beta_{3, m 2}$.

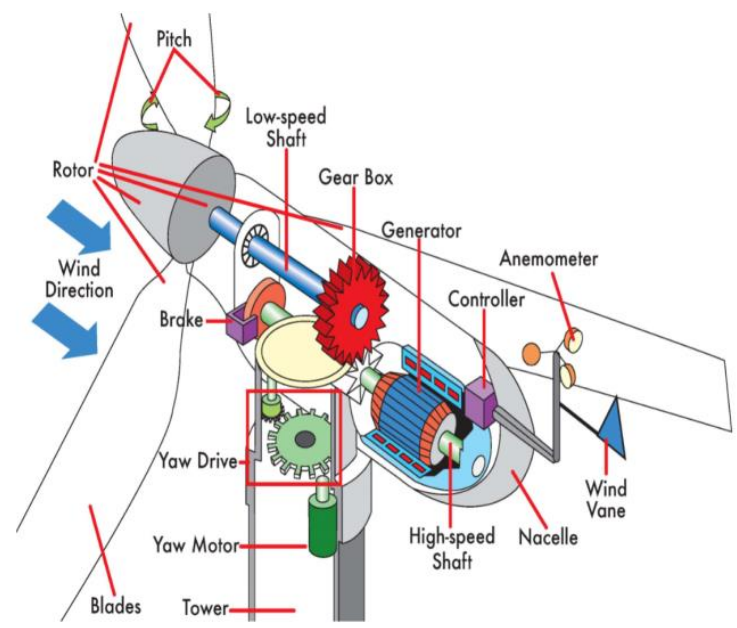

Fig. 1. Conversion of the kinetic energy of the wind

The blades turn the rotor and generate a rotor torque $\tau_{r}$ to the drive train. The drive train converts the rotor torque and the generator torque $\tau_{g}$ to the rotor speed $w_{r}$ and the generator speed $w_{g}$. They are both measured by two sensors as $w_{r, m 1}, w_{r, m 2}$ and $w_{g, m 1}, w_{g, m 2}$. (Shown as $w_{r, m}$ and $w_{g, m}$. In Figure 2, the generator and converter use the generator reference torque $\tau_{g, r}$ to get the generator torque $\tau_{g}$ which is measured as $\tau_{g, m}$. Combined with the generator speed $w_{g}$, we can get the generator power $P_{g}$. A controller is used to let the output power $P_{g}$ follow the reference power denoted $P_{r}$ [25].

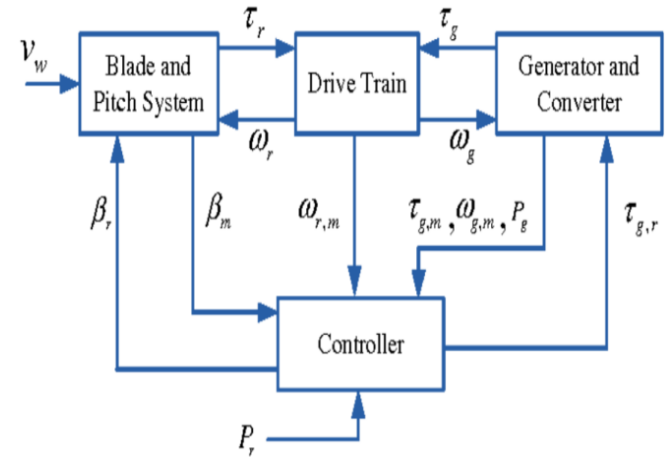

Fig. 2. Overview of the benchmark model

\subsection{Modeling of the constituent components of a wind turbine}

There are several possible configurations of wind turbines which can have significant differences, depending on their use. However, the wind system model in this work consists mainly of wind model, aerodynamic model, pitch angle system model, the drive train model and the model of the generator and the converter.

\subsubsection{Wind model}

The wind turbine is designed to produce overpower a range of speed that goes from $5 \mathrm{~m} / \mathrm{s}$ to $20 \mathrm{~m} / \mathrm{s}$ which is shown in Figure 3. The wind model used as an input for the turbine in the operating speeds is simulated by.

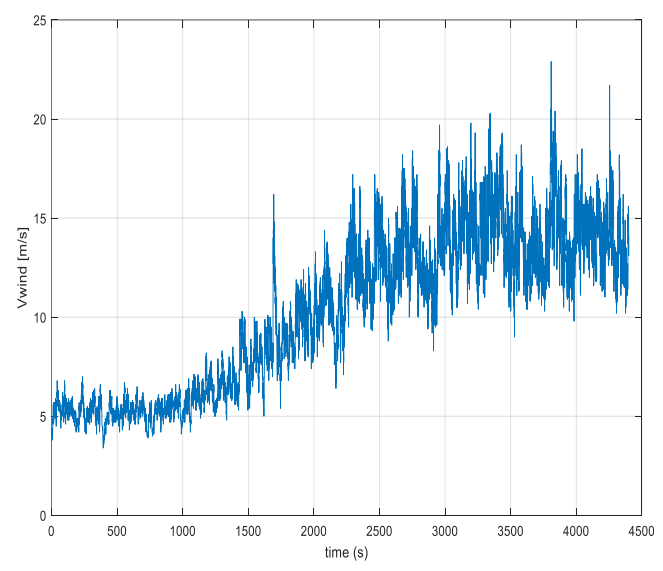

Fig. 3. Wind variation used in benchmark model

\subsubsection{Aerodynamic model}

The wind turbine captures the kinetic energy from the wind and converts it to the torque that turns the rotor blades. The total power $P_{w}$ available in the wind likely to be collected by the blades can be written in the form:

$$
P w=\frac{1}{2} \rho \pi R^{2} V_{w}^{3}
$$

where $V_{w}$ is the wind speed, $\rho=1.225$ is the air density, $R$ is the radius of the blades. 
The apparent power which is the effective power for the turbine is given by:

$$
\begin{aligned}
& P_{a}=P_{w} \cdot C_{P}(\lambda, \beta) \\
& \Rightarrow P_{a}=\frac{1}{2} \rho \pi R^{2} V_{t}^{3} \cdot C_{P}(\lambda, \beta)
\end{aligned}
$$

where $C_{P}(\lambda, \beta)$ is the power coefficient, $\lambda$ is the tip speed ratio, $\beta$ is the pitch angle.

The tip speed ratio is given by:

$$
\lambda=\frac{w_{r} \cdot R}{v_{t}}
$$

where $w_{r}$ is the angular rotor speed.

The key function of aerodynamics in the wind turbine is to generate the torque $\tau_{g}$ by using the force that comes when the wind interacts with the three blades. Rotor torque $\tau_{r}$ can be expressed as:

$$
\tau_{r}=\sum_{1 \leq i \leq 3} \frac{\rho \cdot \pi \cdot V_{t}^{2} \cdot C_{P}\left(\lambda, \beta_{i}\right)}{6}
$$

where $\beta_{i}$ the corresponding blade position $(i=1,2$, 3).

\subsubsection{Pitch angle system model}

The system consists of three identical actuators in Figure (1), each actuator has an internal controller [5, 11]. From now on, it describes only a single actuator. This actuator adjusts the pitch of the blades angle by rotating. This hydraulic actuator is modeled as $2^{\text {rd }}$ order state-space model such that:

$$
\begin{aligned}
& {\left[\begin{array}{c}
\dot{W}_{b} \\
\dot{\beta}_{i}
\end{array}\right]=A_{p b}\left[\begin{array}{c}
W_{b} \\
\beta_{i}
\end{array}\right]+\beta_{p b}\left[\beta_{r}-\beta_{i f}\right]} \\
& y_{p b}=C_{p b}\left[\begin{array}{c}
W_{b} \\
\beta_{i}
\end{array}\right]
\end{aligned}
$$

With $\quad A_{p b}=\left[\begin{array}{cc}-13.332 & 123.4321 \\ 1 & 0\end{array}\right], B_{p b}=\left[\begin{array}{l}1 \\ 0\end{array}\right]$, $C_{p b}=\left[\begin{array}{ll}1 & 0\end{array}\right]$.

where $\dot{\beta}_{i}$ is physical pitch angle $((i=1,2,3)$, $w_{b}=\dot{\beta}_{i}$ is the pitch angular speed, $y_{p b} \in \mathfrak{R}$ is the measured pitch position $\dot{\beta}_{i}, \beta_{r} \in \mathfrak{R}$ is the reference position to the controller.

\subsubsection{Drive train model}

In this benchmark model, the drive train is modeled by a two-mass drive train model. The purpose of the drive train is to transfer torque from the rotor to the generator. It includes a gearbox that increases the rotational speed from the low-speed rotor side to the high-speed generator side. The state-space model of the drive train is given by $[5$, $25,27]$.

$$
\left[\begin{array}{c}
\dot{\omega}_{r(t)} \\
\dot{\omega}_{g(t)} \\
\dot{\theta}_{\Delta(t)}
\end{array}\right]=A_{d t}\left[\begin{array}{c}
\omega_{r(t)} \\
\omega_{g(t)} \\
\theta_{\Delta(t)}
\end{array}\right]+\beta_{d t}\left[\begin{array}{c}
\tau_{r(t)} \\
\tau_{g(t)}
\end{array}\right]
$$

And the output of the state-space model of the drive train is given by $[5,25,27]$ :

$$
y_{d t}=C_{d t}\left[\begin{array}{l}
\omega_{r(t)} \\
\omega_{g(t)} \\
\theta_{\Delta(t)}
\end{array}\right]
$$

\subsubsection{Model of the generator and converter}

In this section, the converter and generator models are presented. The generator converts the mechanical energy into electrical energy, while it is loaded by a torsion moment issued by the converter. It is described as a first-order system.

$$
\frac{\tau_{g}(s)}{\tau_{g, S}(s)}=\frac{\alpha_{g c}}{S+\alpha_{g s}}
$$

where $\alpha_{g c}=50, \tau_{g, r}(s)$ is the generator torque reference.

The power produced by the generator depends on the angular speed of the generator, as described in the following equation:

$$
P_{g}(t)=\eta_{g c} \omega_{g} \tau_{g}(t)
$$

where $\eta_{g c}=0.98$ is a constant representing the generator efficiency.

\subsection{Sensor models}

Some relevant faults are considered in this benchmark model. The first is a fault in the pitch position measurements. These faults are denoted $\beta_{1, m 1}, \beta_{1, m 2}, \beta_{2, m 1}, \beta_{2, m 2}, \beta_{3, m 1}, \beta_{3, m 2}$. Secondly, the rotor speed measurement can be faulty. We denote the deviations in rotor speed measurement caused by these faults as $w_{r, m 1}$ and $w_{r, m 2}$. The fault signals for the two generator speed measurements are denoted a $w_{g, m 1}$ and $w_{g, m 2}$. Both the rotor and generator speed measurements are done using encoders. Encoder faults can be due to both electrical and mechanical failures, which result in either a fixed value or a changed gain factor on the measurements[13, 18] .

\subsubsection{Fault scenarios}

Several faults are considered in the benchmark model. Some are sensor faults which could happen in pitch position measurements $\beta_{1, m 1}, \beta_{1, m 2}, \beta_{2, m 1}$, $\beta_{2, m 2}, \quad \beta_{3, m 1}, \quad \beta_{3, m 2}$, rotor speed measurements $w_{r, m 1}, w_{r, m 2}$ and generator speed measurements 
$w_{g, m 1}, w_{g, m 2}$. Some are actuator faults which may happen in the converter and pitch systems denoted as $\Delta \tau_{g, r}, \Delta \beta_{i}(\mathrm{i}=1,2,3)$ [18]. The possible failure scenarios which may be presented as follows:

- Fault 1: fault type A1, a fixed value on $\beta_{1, m 1}$ equal to $5^{\circ}$ in the period from 2000 to $2100 \mathrm{~s}$,

- Fault 2: fault type A2, a gain factor on $\beta_{2, m 2}$ equal to 1.2 in the period from 2300 to $2400 \mathrm{~s}$,

- Fault 3: fault type A1, a fixed value on $\beta_{3, m 1}$ equal to $10^{\circ}$ in the period from 2600 to $2700 \mathrm{~s}$,

- Fault 4: fault type A3, a fixed value on $w_{r, m 1}$ equal to $1.4 \mathrm{rad} / \mathrm{s}$, in the period from 1500 to $1600 \mathrm{~s}$,

- Fault 5: fault types A4 and A6, gain factors on $w_{r, m 2}$ and $w_{g, m 1}$, respectively, equal to 1.1 and 0.9 in the period from 1000 to $1100 \mathrm{~s}$,

- Fault 6: fault type B3, change in the dynamics due to the hydraulic pressure drop of the pitch actuator 2; the fault is assumed to be abrupt and it is present in the period from 2900 to $3000 \mathrm{~s}$,

- Fault 7: Fault type B4, change in the dynamics due to increased air content in the oil on pitch actuator 3 . The fault is slowly introduced during $30 \mathrm{~s}$ with a constant rate; afterward, the fault is active during $40 \mathrm{~s}$, and again decreases during $30 \mathrm{~s}$. The fault begins at $3500 \mathrm{~s}$ and ends at $3600 \mathrm{~s}$,

- Fault 8: fault type B2, an offset on $\tau_{g}$ of the value $100 \mathrm{Nm}$, the fault is active from 3800 to $3900 \mathrm{~s}$.

\subsection{Observers based diagnosis of wind turbine}

By definition, an observer is a dynamic system taking to input the known signals of the system on which it is implanted and whose outputs converge towards estimation of the state variables (or of a part of the state variables).

The main idea of the observer-based diagnosis is to estimate a part where the set of system measurements that are monitored from measurable magnitudes. This estimate is compared to the measured value of the output to generate residuals. These residues should serve as reliable indicators of the behavior of our system. They are therefore void in the absence of defects and not null in their presence [19]. The proposed Unknown Input Observer-based Fault Tolerant Control scheme consists of a bank of observers, each designed for the different fault scenarios: No Faults (Observer 1), a fault in one rotor speed sensor (Observer 2), a fault in one generator speed sensor (Observer 3), faults in both rotor speed sensors (Observer 4), faults in both generator speed sensors (Observer 5) and a fault in one generator speed sensor and one rotor speed sensor (Observer 6). These unknown input observers are designed using the scheme presented in $[13,18,26]$. These 6 designs cover all the possible combinations of faults since the observer does not matter which of the two respective sensors of one speed is faulty since these sensors are only modeled by stochastic noise added to the actual speed value. It is assumed that the model of the wind turbine can be represented by a discrete-time state-space model of the form.

$$
\begin{aligned}
& X[n+1]=A_{d} X[n]+B_{d} U[n]+E_{d} d[n]+\varepsilon[n] \\
& Y_{j}[n]=C_{d, j} X[n]+\eta[n]
\end{aligned}
$$

where $X[n]$ is the state vector.

However, the system inputs will be presented in the following state vector :

$$
U[n]=\left[\begin{array}{c}
\tau_{\text {gen,r } r}[n] \\
\tau_{\text {earo }}[n]
\end{array}\right]
$$

Where $Y_{j}[n]$ defines a vector of sensor signals, corresponding to the $j_{t h}$ observer. They are given below and for those coefficients, without a number, it indicates that only one of these sensors is healthy.

$$
Y_{j}[n]=\left[\begin{array}{c}
\omega_{r, m 1}[n] \\
\omega_{r, m 2}[n] \\
\omega_{g, m 1}[n] \\
\omega_{g, m 2}[n]
\end{array}\right]
$$

Where $d[n]$ a vector of unknown inputs is, $\varepsilon[n]$ defines the process noise, $\eta[n]$ defines the measurement noise. The discrete-time model matrices are given as $A_{d}, B_{d}, E_{d}$ and $C_{d, i}$ which denotes the $C_{d}$ matrix for the $j_{t h}$ observer.

The unknown input observer in the discretetime form is given by $[13,15,20]$. In this formulation of the observer the subscript index $\mathrm{j}$ refers to the observer number.

$$
\begin{aligned}
& Z[n+1]=F_{j} Z[n-1]+T_{j} d U[n-1]+K j Y j \\
& x[n]=Z[n] H_{j} Y_{j}[n]
\end{aligned}
$$

All observers are computed at each sample but the vectors $x[n]$ and $Z[n]$ are given as $x_{i}[n]$ and $Z_{i}[n]$ where $i$ corresponds to the observer number accommodating the detected and isolated faults at sample $n$.

\subsection{Wind turbine control}

The objective of this part is to explain how the variation of wind speed and the pitch angle influence the control of power and also to explain 
the variables that are involved in this control. This is very important because the diagnosis and faulttolerant control are applied under these conditions, indeed the wind turbine works in four zones depending on the wind speed, shown in Figure 4.

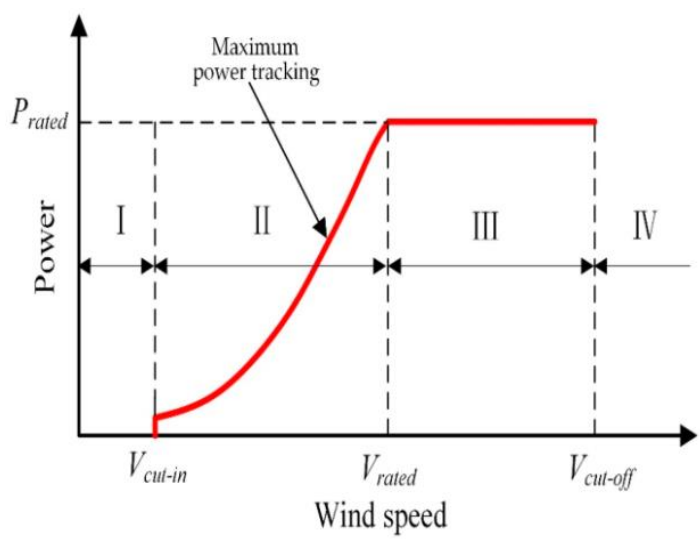

Fig. 4. Typical wind turbine output power

The output power curve for the wind turbine depends on the wind speed. In zone 1, the wind turbine will be idling awaiting higher wind speeds $(0-5 \mathrm{~m} / \mathrm{s})$. In zone 2 , the generated power of the wind turbine will be optimized $(5-12.5 \mathrm{~m} / \mathrm{s})$. In zone 3, the wind turbine will be controlled to keep a constant power generation (12.5-25 m/s). In zone 4, the wind turbine will be parked, preventing damage due to the high wind speed (above $25 \mathrm{~m} / \mathrm{s}$ ).

The controller is active in zones II and III. In area II the optimal speed of the rotor is obtained by using the torque converter as a control signal. Zone III corresponds to constant power output. In this work, only zones II and III are considered to achieve this propose, we compare to control approach the PI control and the fuzzy logic control $[14,22]$.

\subsubsection{PI Controller}

The controller is implemented with a sampling frequency of $100 \mathrm{~Hz}$. The control mode should switch from 1 to 2 if:

$$
P_{g}[n] \geq P_{r}[n] \wedge \omega_{g}[n] \geq \omega_{\text {nom }}[n]
$$

where $w_{\text {nom }}=162 \mathrm{red} / \mathrm{s}$.

The control mode should switch from 2 to 1 if:

$$
\omega_{g}[n] \leq \omega_{\text {nom }}[n]-\omega_{\Delta}
$$

The $\omega_{\Delta}$ is a small offset subtracted from the nominal generator speed.

\section{- Control mode 1:}

The converter reference signal in this control mode is defined by the $\beta_{r}[n]=0$ and the reference torque to the converter $\tau_{g . r}$ as follows:

$$
\tau_{g . r}=K_{o p t}\left(\frac{\omega_{g}}{N_{g}}\right)^{2}
$$

With:

$$
K_{\text {opt }}=\frac{1}{2} \rho \cdot \pi \cdot R^{3} \frac{C_{p}(\lambda, \beta)}{\lambda^{3}}
$$

\section{- Control Mode 2:}

The converter reference signal in this control mode is given by $\beta_{r}[n]$ as follows :

$$
\begin{aligned}
& \beta_{r}[n]=\beta_{r}[n-1]+k_{p} e[n]+ \\
& \left(k_{i} \cdot T_{s}-k_{p}\right) e[n-1]
\end{aligned}
$$

Where $e[n]=w_{g}[n]-w_{n o m}[n]$ in this case, the converter reference is used to suppress fast disturbances given by:

$$
\tau_{g . r}[n]=\frac{P_{g}[n]}{\eta_{g c} . \omega_{g}[n]}
$$

Table I : Wind model parameters used in the benchmark model

\begin{tabular}{|l|l|l|}
\hline$\alpha$ & $\mathrm{H}$ & $r_{0}$ \\
\hline 0.1 & $81 \mathrm{~m}$ & $1.5 \mathrm{~m}$ \\
\hline
\end{tabular}

Table II : Blade and pitch model parameters used in the benchmark model

\begin{tabular}{|l|l|l|l|}
\hline $\mathrm{R}$ & $\sigma$ & $\xi$ & $\omega_{n}$ \\
\hline $57.5 \mathrm{~m}$ & $1.225 \frac{\mathrm{k}_{g}}{\mathrm{~m}^{3}}$ & 0.6 & $1.225 \frac{\mathrm{rad}}{\mathrm{s}}$ \\
\hline$\xi_{2}$ & $\omega_{n 2}$ & $\xi_{3}$ & $\omega_{n 3}$ \\
\hline 0.45 & $5.73 \frac{\mathrm{rad}}{\mathrm{s}}$ & 0.9 & $3.42 \frac{\mathrm{rad}}{\mathrm{s}}$ \\
\hline
\end{tabular}

Table III: Drive train model parameters used in the

\begin{tabular}{|c|c|c|c|}
\hline \multicolumn{4}{|c|}{ benchmark model } \\
\hline $775.49 \frac{\mathrm{Nms}}{\mathrm{rad}}$ & $7.11 \frac{\mathrm{Nms}}{\mathrm{rad}}$ & $45.6 \frac{\mathrm{Nms}}{\mathrm{rad}}$ & $B_{g}$ \\
\hline$K_{d t}$ & $\eta_{d t}$ & $\eta_{d t 2}$ & $J_{g}$ \\
\hline $2,7.10^{9} \frac{\mathrm{Nms}}{\mathrm{rad}}$ & 0.97 & 0.92 & $390 \mathrm{~kg} \cdot \mathrm{m}^{2}$ \\
\hline$J_{r}$ & - & & \\
\hline $55.10^{6} \mathrm{Kg} . \mathrm{m}^{2}$ & - & - & - \\
\hline
\end{tabular}

\subsubsection{Fuzzy Logic control}

Today, fuzzy logic came to maturity and used in many industrial and managerial applications, its implementation is now facility with the availability of dedicated microprocessors and powerful tools for development [24, 26, 28]. This section deals with the decomposition of input-output data $u(t)$ and $y(t)$, acquired from the actual process, into fuzzy 
subsets, which are approximated by local affine input-output models. Fuzzy clustering algorithms can be used as a tool to obtain partitioning of data into subsets, which can be approximated by local affine models. It is assumed that the dynamics of the system under observation is described by the following Equation Error (EE) [26].

$$
y(t)=f(x(t))+\varepsilon(t)
$$

where the vector $y(t)$ is the system output, $x(t)$ is a collection of a finite number of inputs and outputs, the vector $x^{t}(t)=[y(t-1), \ldots, y(t-n), u(t-1), \ldots, u(t-n)], \quad f($. describes the input-output link, while $\varepsilon(t)$ reflects the fact that $y(t)$ is not an exact function of $x(t), \mathrm{n}$ is an integer related to the system memory or order. Generally, the treatment of a problem by fuzzy logic is done in three steps.

The objective of fuzzy clustering algorithms is to partition the set of observed inputs and outputs $x(t)$ of an unknown system into a number $M$ of fuzzy subsets. Each subset, $R_{i}(i=1, M)$ representing an operating condition of the dynamic system, can be approximated by an affine dynamic model. Partition of the data set into a fuzzy subset can be achieved, for instance, by using the wellestablished Gustafson-Kessel (GK) clustering algorithm [26]. Each cluster $R_{i}$ of the data $x_{i}(t)$ obtained by fuzzy partitioning is regarded as a local approximation of the real process. The global EE model (1) can be conveniently represented using local affine Takagi-Sugeno rules $y_{i}(t)$ given by:

$$
x(t) \in R_{i} \Rightarrow y_{i}=\theta_{i}^{T} x(t)
$$

Where $\theta_{i}$ is the $i-t h$ parameter vector of the $i-t h$ sub-model, with $i=1, \ldots, M$. The TakagiSugeno fuzzy model is a simple way to describe a nonlinear dynamic system using local affine models. The global system behavior is thus described by a fuzzy fusion of all affine model outputs:

$$
\hat{y}(t)=\frac{\sum_{i=1}^{M} \mu_{i}(x(t)) y_{i}(t)}{\sum_{i=1}^{M} \mu_{i}(x(t))}
$$

In which $\hat{y}(t)$ is the estimate of the output $y(t)$ at the instant $t$. The results of the clustering algorithms are $M$ the membership functions $\mu_{i}$, and the subsets of input-output data $(x(t))_{i=1}^{T}$ with $t \in \mathfrak{R}_{i}$

\section{APPLICATIONS RESULTS}

The model developed by kk-electronic is presented for a turbine $4.8 \mathrm{MW}$ for a given wind profile previously, for the investigation and tests of the proposed approach, the actual operating data of the studied wind turbine was used in the PI controller, to present the dynamics of the turbine in operational mode.

We note that between $(t=0$ to $t=2300 \mathrm{~s})$, wind speed is in zone 2, hence the value of pitch angle and the resulting power is optimal. From $(t>2300$ s) the wind speed can reach area (zone 3 ), one can notice that the power, torque, and speed are controlled at their nominal values. The pitch angle is equal to 0 in this case.

Eight faults were detected and isolated simultaneously in this scenario. Fig. 5 shows the electrical power generated in this scenario. We find that the production of energy is influenced by the command. We observe a fault between the instants $2600 \mathrm{~s}$ and $2700 \mathrm{~s}$. This is due to a fault in the fixed value. From the results, we notice that a good power tracking of the fuzzy regulator compared to the classic PI (the results of which were presented to the generator electric power), we obtained an improvement in the overall performance of the system.

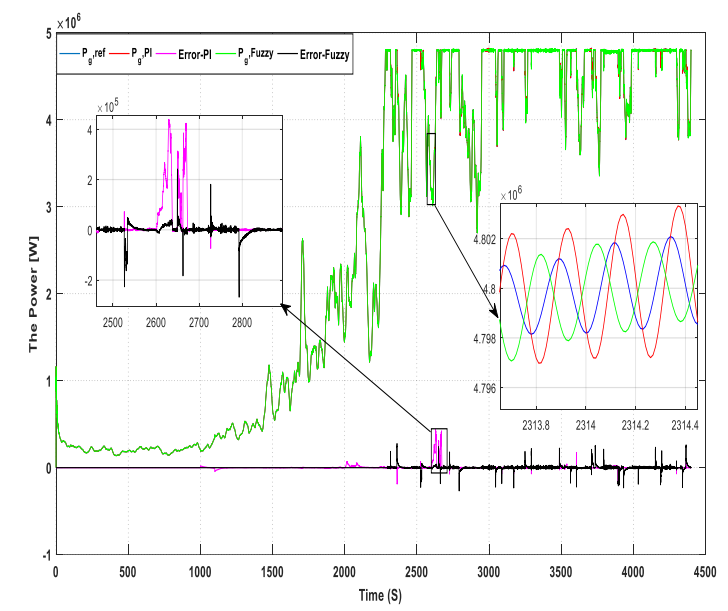

Fig. 5. Variation of the electric power of the examined wind turbine

Fig. 6 shows the torque generated $\tau_{g}$ in this scenario. We find that the production of energy is influenced by the command, we observe a fault between the instants $3800 \mathrm{~s}$ and $3900 \mathrm{~s}$, this is caused by the fault 8 , shown in the Fig 6 .A in the fixed value. From this results, we notice a good speed tracking, and a good rejection of disturbances. 


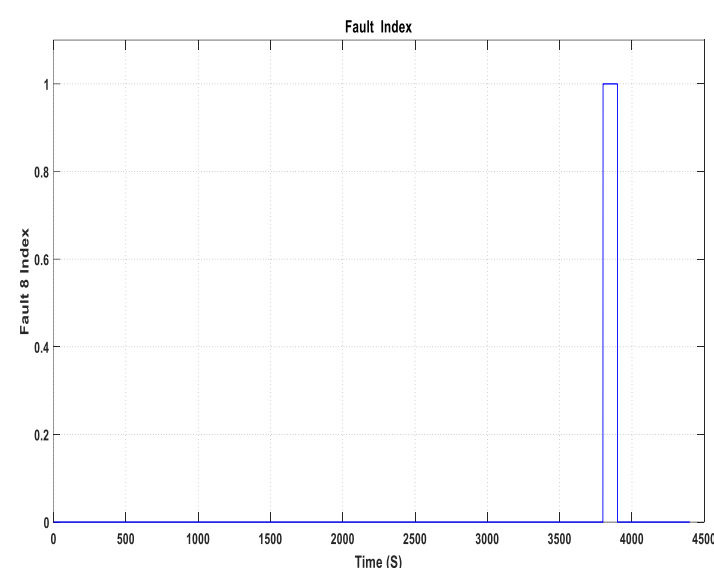

Fig. 6.A. Fault 8 signal

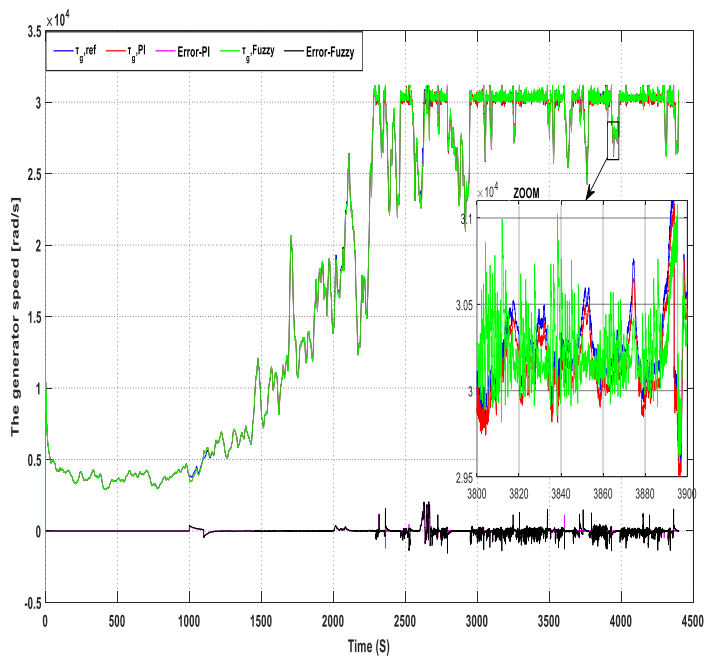

Fig. 6. Variation of the generator torque of the examined wind turbine

Fig. 7 shows the sensor measurements on $w_{r, m 2}$ and $w_{g, m 1}$ the result of the fault decision, we notice the existence of a defect, of type gain factors, it's the fault 5 shown in the Fig.7.A, it appears between the instants $1000 \mathrm{~s}$ and $1100 \mathrm{~s}$, where the measurement of $w_{g, m 1}$ which is also influenced by disturbances. From this results, we notice a good speed tracking, with an almost zero overshoot of the fuzzy governor, and a good rejection of disturbances.

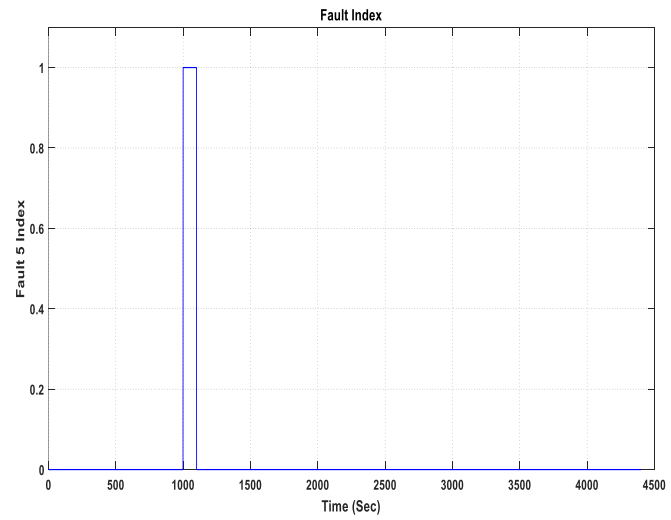

Fig. 7.A. Fault 5 signal

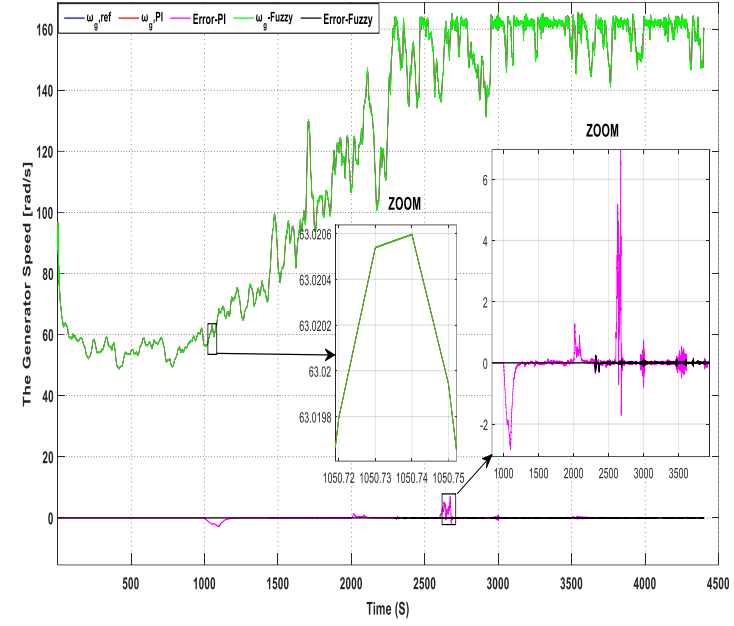

Fig. 7. Variation of the generator speed of the examined wind turbine

Fig. 8 shows the sensor measurements on $w_{r, m 1}$ the result of the fault decision, we notice the existence of a defect, of type gain factors, caused by the fault 4 shown in the Fig.8.A, it appears between the instants 1500 s and 1600s. From this results, we notice a good speed tracking, and a good rejection of disturbances.

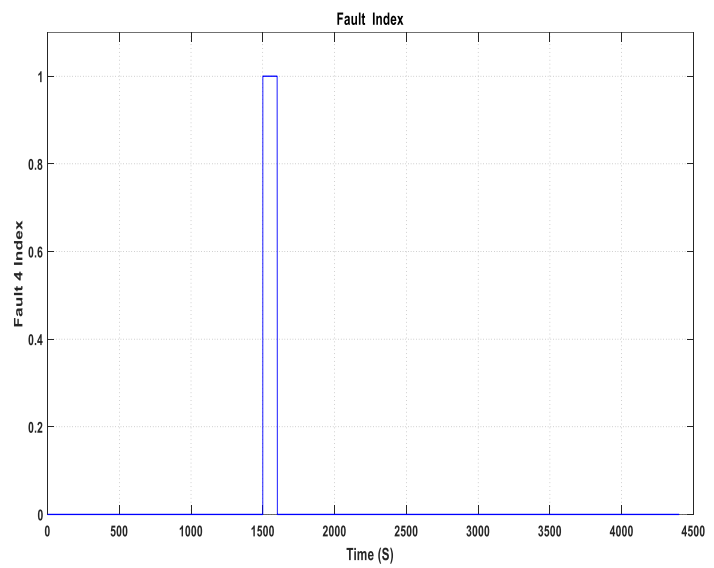

Fig. 8.A. Fault 4 signal

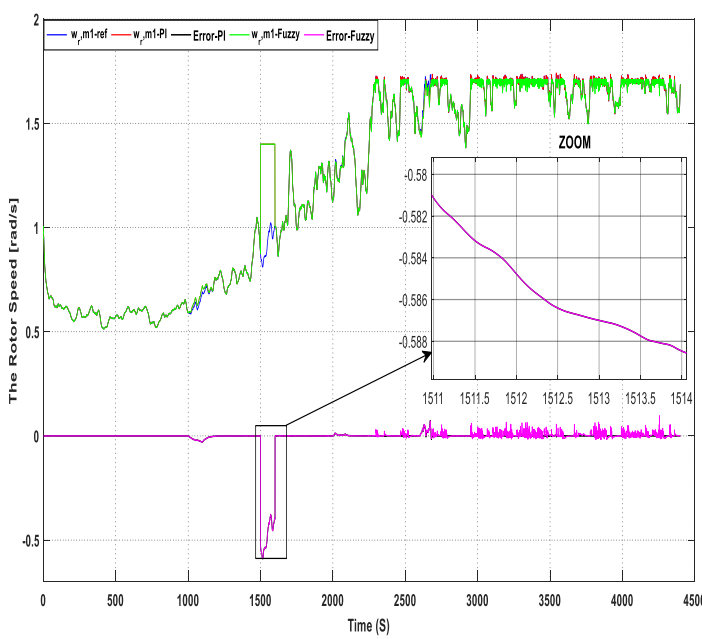

Fig. 8. Variation of the rotor speed of the examined wind turbine 
Fig. 9 and Fig.10 shows the sensor measurements $\beta_{1, m 1}$ and the fault result. We notice the presence of a fixed value defect. This is the fault 1 shown in Fig.9.A, it's detected and isolated between the instants 2000s and 2100s. From this results, we notice that overall investigating the factors, the fuzzy control strategy shows better performance in comparison with the PI control strategy.

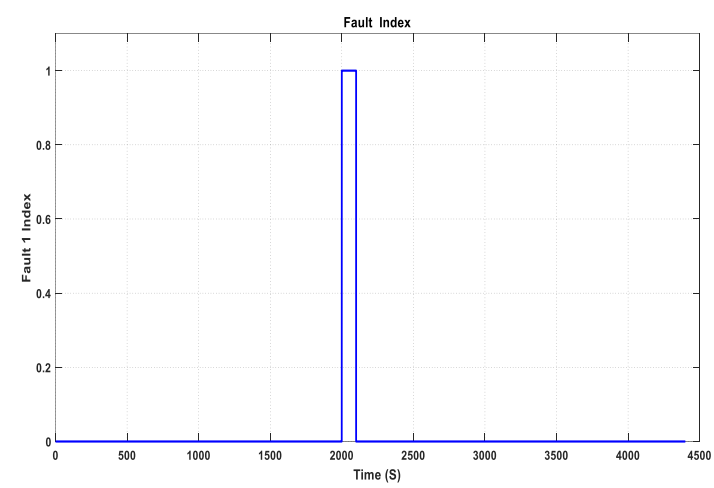

Fig. 9.A. Fault 1 signal

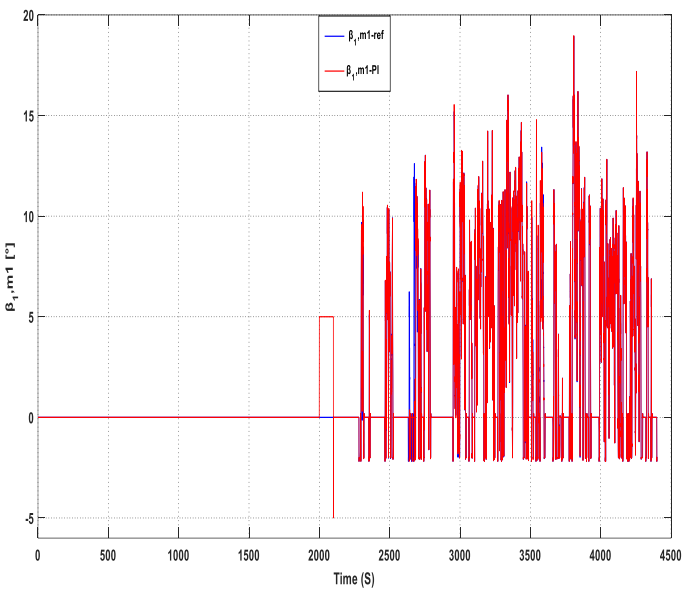

Fig.9. Detection and isolation of fault 1 on the sensor $\beta_{1,1}$ using PI controller

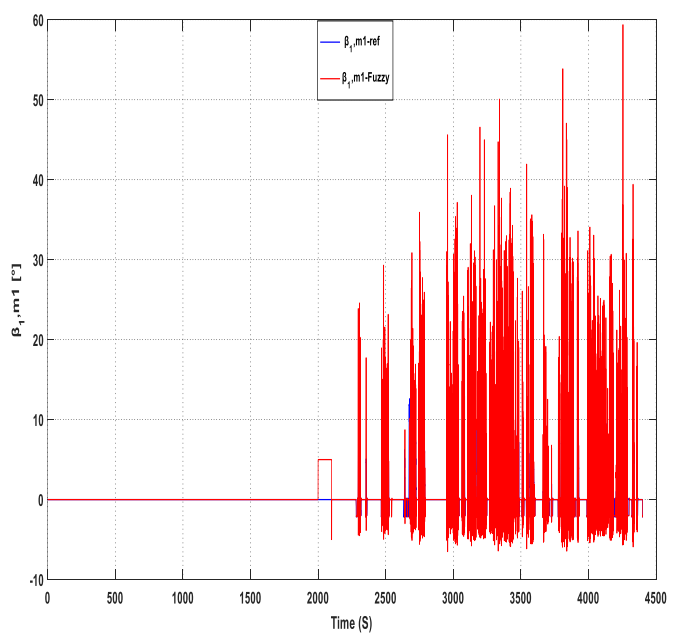

Fig.10. Detection and isolation of fault 1 on the sensor $\beta_{1,1}$ using fuzzy controller
Fig.11 and Fig.12 show the detection of the fault 2, shown in Fig.11.B, is a fault $\beta_{2, m 2}$ in the scaling error sensor in one of the two-blade position sensors 2, and fault 6, shown in Fig.11.A, is a fault type B3 in the actuator caused by high air content in the oil pitch actuator 2. From this results, we notice that overall investigating the factors, the fuzzy control strategy shows better performance in comparison with the PI control strategy.

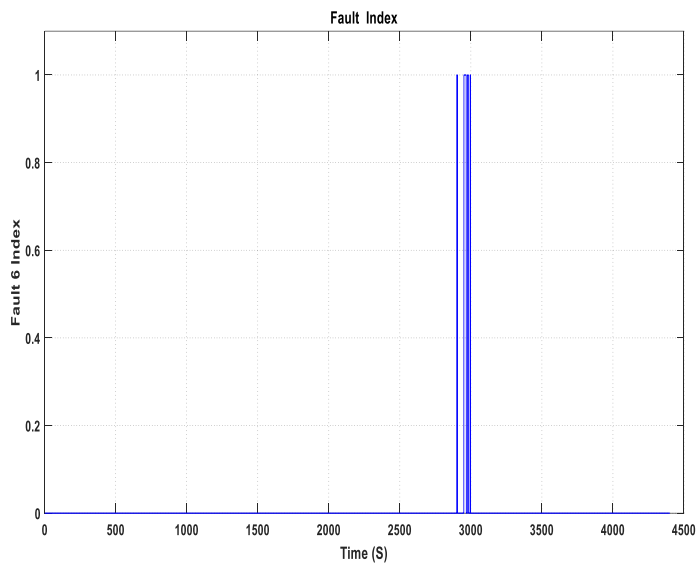

Fig.11.A. Fault 6 signal

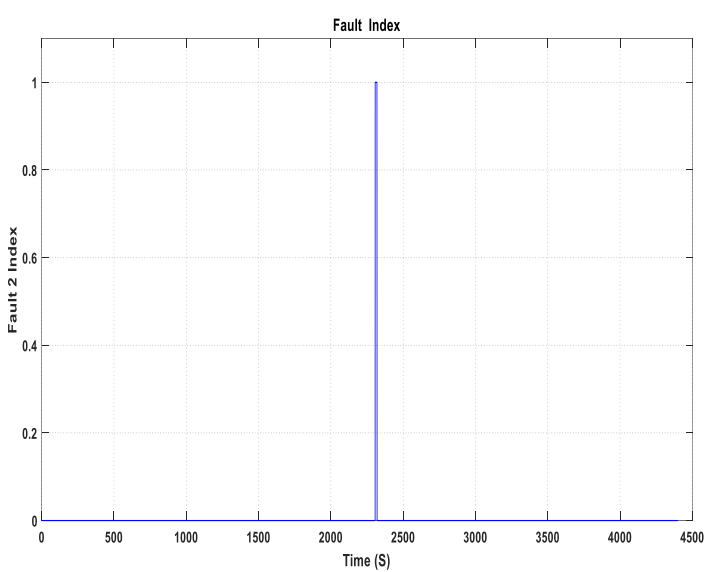

Fig.11.B. Fault 2 signal

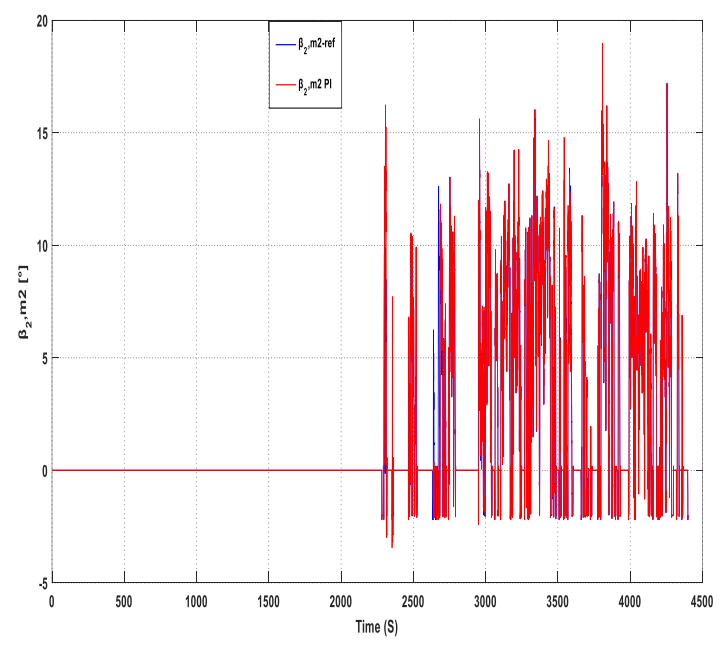

Fig. 11. Detection and isolation of fault 2 on the sensor $\beta_{2,2}$ and fault 6 the controller PI 


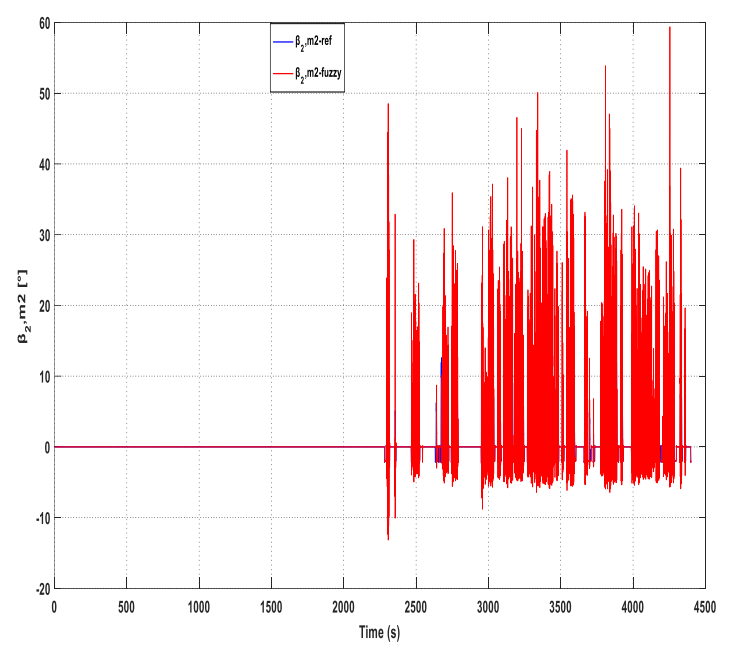

Fig. 12. Detection and isolation of fault 2 on the sensor $\beta_{2,2}$ and fault 6 the fuzzy controller

Fig.13 and Fig.14 show the detection of fault 3, shown in Fig. 13.A, is a fault $\beta_{3, m 1}$ in the scaling error sensor in one of the two-blade position sensors 1, and fault 7 shown in Fig.13.B, is a fault type B3 in the actuator caused by high air content in the oil pitch actuator 3 . From this results, we notice that overall investigating the factors, the fuzzy control strategy shows better performance in comparison with the PI control strategy.

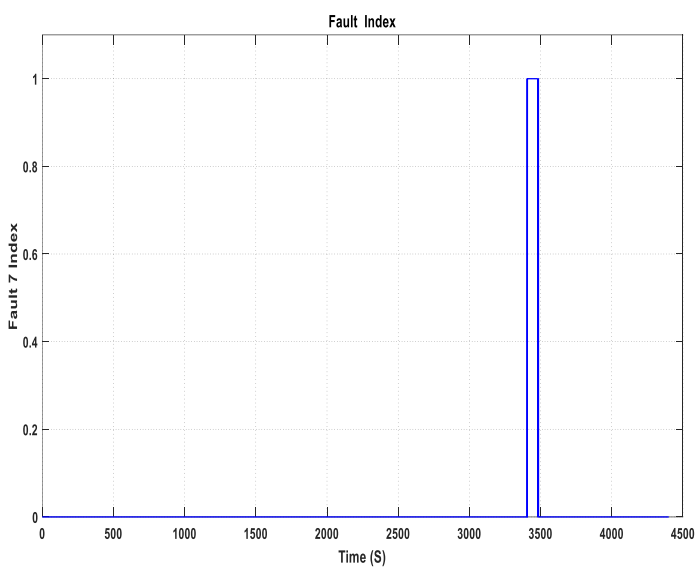

Fig. 13.A. Fault 3 signal

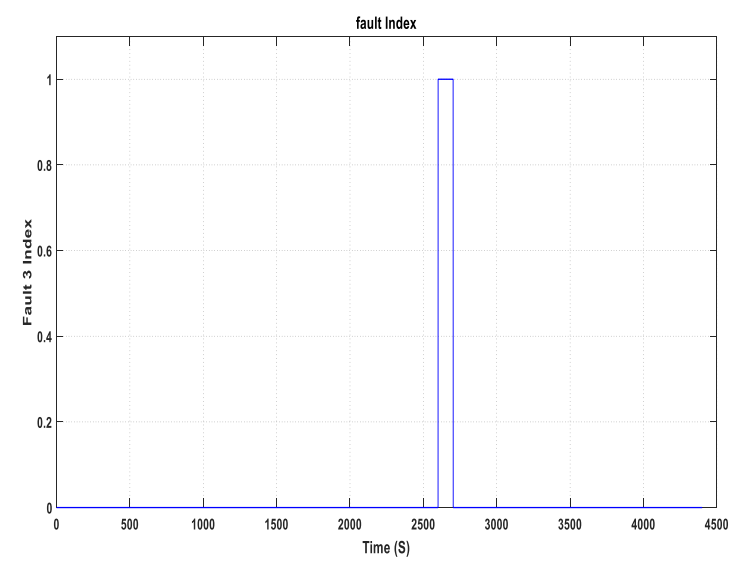

Fig. 13.B. Fault 7 signal

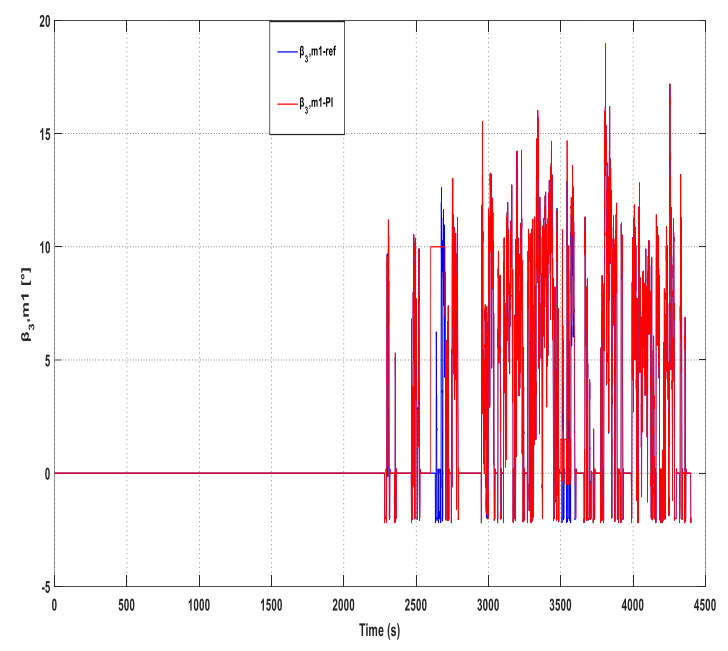

Fig. 13. Detection and isolation of fault 3 on the sensor $\beta_{3,1}$ and fault 7 the PI controller

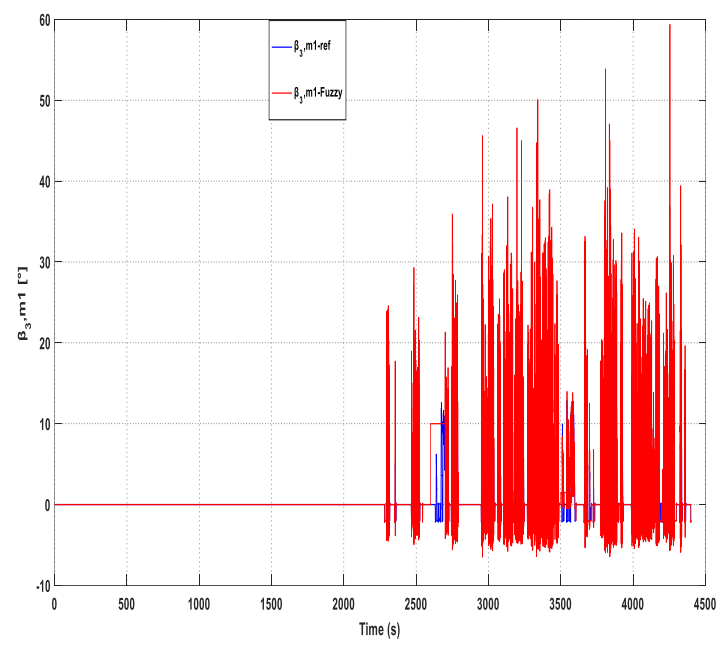

Fig. 14. Detection and isolation of fault 3 on the sensor $\beta_{3,1}$ and fault 7 the fuzzy controller

From the obtained results, it can be seen that before time $\mathrm{t}=2100 \mathrm{~s}$ (zone 2), faults 1,4 , and 5 can reduce power and increase torque. However, the control has no input on this fault (zone 2). After $\mathrm{t}=2100 \mathrm{~s}$ (zone 3) logical control to destitute the effect of faults $2,3,6,7$, and 8 for the control of power. The same for the torque and speed of the generator.

After the step of generating the residues that are presented in the paper, the next task is their evaluation for fault detection. For this, the fuzzy model has been proposed to determine and to localize the type of faults that affect the wind turbine system based on the residues generated previously. Indeed, the method detected and studied system statistical of change characteristics. The results presented in this work show the effectiveness of the proposed diagnostic system. 


\section{CONCLUSION}

In this work, the control of the wind system based on the benchmark model is studied, concerns the diagnosis, and passive fault-tolerant control for different failure, applied to a model of wind Benchmark. The bunch of observers for the detection and location of defects in wind 'Benchmark' model was used, the defects which have been taken into account are defects of sensor and actuator faults. Finally, a passive FTC architecture is examined, using the order laws of the fuzzy controller and investigate the effect of the opposite law order of defects.

\section{REFERENCES}

1. Odgaard PF, Stoustrup J. Fault tolerant wind speed estimator used in wind turbine controllers. The 8th IFAC Symposium on Fault Detection, Supervision and Safety of Technical Processes, August 29-31. National Autonomous University of Mexico, Mexico City, Mexico., 2012.

2. Ahmet Arda Ozdemir, Peter Seiler, Gary J. Balas. Wind turbine fault detection using counter-based residual thresholding. IFAC Proceedings Volumes 2011;44(1):8289-8294. https://doi.org/10.3182/20110828-6-IT-1002.01758

3. Ali El Yaakoubi, Kamal Attari, Adel Asselman, Abdelouahed Djebli. Novel power capture optimization based sensor less maximum power point tracking strategy and internal model controller for wind turbines systems driven SCIG. Frontiers in Energy 2019;13:742-756. https://doi.org/10.1007/s11708-017-0462-x

4. Atif Iqbal, Deng Ying, Adeel Saleem, Muhammad Aftab Hayat, Kashif Mehmood. Efficacious pitch angle control of variable-speed wind turbine using fuzzy based predictive controller. Energy Reports 2020;6:423-427.

https://doi.org/10.1016/j.egyr.2019.11.097

5. Aylin Adem, Ali Çolak, Metin Dağdeviren. An integrated model using SWOT analysis and hesitant fuzzy linguistic term set for evaluation occupational safety risks in life cycle of wind turbine. Safety Science 2018;106:184-190. https://doi.org/10.1016/j.ssci.2018.02.033

6. Ayoub EL Bakri, Ismail Boumhidi. Fuzzy modelbased faults diagnosis of the wind turbine benchmark. Procedia Computer Science 2018; 127: 464-470. https://doi.org/10.1016/j.procs.2018.01.144

7. Benchabane F, Titaouine A, Bennis O, Guettaf A, Yahia K, Taibi D. An improved efficiency of fuzzy sliding mode control of permanent magnet synchronous motor for wind turbine generator pumping system. Applied Solar Energy 2012;48:112117. https://doi.org/10.3103/S0003701X12020089

8. Bounar N, Labdai S, Boulkroune A, Farza M, M'Saad M. Adaptive fuzzy control scheme for variable speed wind turbines based on a doubly fed induction generator. Iranian Journal of Science and Technology, Transactions of Electrical Engineering 2020; 44: 629-641. https://doi.org/10.1007/s40998019-00276-6

9. Carl Svärd, Mattias Nyberg. Automated design of an FDI system for the wind turbine Benchmark. IFAC
Proceedings Volumes 2011; 44(1): 8307-8315. https://doi.org/10.3182/20110828-6-IT-1002.00618

10. Colombo L, Corradini ML, Ippoliti G, Orlando G. Pitch angle control of a wind turbine operating above the rated wind speed: A sliding mode control approach. ISA Transactions 2020; 96: 95-102. https://doi.org/10.1016/j.isatra.2019.07.002

11. Ester Sales-Setién, Ignacio Peñarrocha-Alós. Robust estimation and diagnosis of wind turbine pitch misalignments at a wind farm level. Renewable Energy 2020; 146: 1746-1765. https://doi.org/10.1016/j.renene.2019.07.133

12. Geev Mokryani, Pierluigi Siano, Antonio Piccolo, Fault ride-through enhancement of wind turbines in distribution networks. Journal of Ambient Intelligence and Humanized Computing 2013; 4: 605-611. https://doi.org/10.1007/s12652-012-0162-7

13. Hamed Badihi, Youmin Zhang, Subhash Rakheja, Pragasen Pillay. Model based fault tolerant pitch control of an offshore wind turbine. IFAC-Papers 2018;51(18):221-226. https://doi.org/10.1016/j.ifacol.2018.09.303

14. Hamed Habibi, Ian Howard, Silvio Simani. Reliability improvement of wind turbine power generation using model-based fault detection and fault tolerant control: A review. Renewable Energy 2019;135:877-896. https://doi.org/10.1016/j.renene.2018.12.066

15. Hossam HH, Mousa, Abdel-Raheem Youssef, Essam EM. Mohamed. Optimal power extraction control schemes for five-phase PMSG based wind generation systems. Engineering Science and Technology, an International Journal 2020; 23(1): 144-155. https://doi.org/10.1016/j.jestch.2019.04.004

16. Hui Shao, Zhiwei Gao, Xiaoxu Liu, Krishna Busawon. Parameter-varying modelling and fault reconstruction for wind turbine systems. Renewable Energy 2018; 116 (Part B): 145-152. https://doi.org/10.1016/j.renene.2017.08.083

17. Mansour Sheikhan, Reza Shahnazi, Ali Nooshad Yousefi, An optimal fuzzy PI controller to capture the maximum power for variable-speed wind turbines. Neural Computing and Applications 2013; 23: 13591368. https://doi.org/10.1007/s00521-012-1081-4

18. Mohamed Abdelkarim Abdelbaky, Xiangjie Liu, Di Jiang. Design and implementation of partial offline fuzzy model-predictive pitch controller for largescale wind-turbines. Renewable Energy 2020; 145: 981-996. https://doi.org/10.1016/j.renene.2019.05.074

19. Mosayeb Bornapour, Amin Khodabakhshian, Mohammad Reza Esmaili. Optimal Multi-objective Placement of Wind Turbines Considering Voltage Stability, Total Loss and Cost Using Fuzzy Adaptive Modified Particle Swarm Optimization Algorithm. Iranian Journal of Science and Technology, Transactions of Electrical Engineering 2019; 43: 343359. https://doi.org/10.1007/s40998-018-0105-1

20. Nassim Laouti, Nida Sheibat-Othman, Sami Othman. Support vector machines for fault detection in wind turbines. IFAC Proceedings, Milan, Italy, 2011; 44(1): 7067-7072. https://doi.org/10.3182/201108286-IT-1002.02560

21. Nassim Laouti, Sami Othman, Mazen Alamir, Nida Sheibat-Othman. Combination of model-based observer and support vector machines for fault detection of wind turbines. International Journal of 
Automation and Computing 2014; 11: 274-287. https://doi.org/10.1007/s11633-014-0790-9

22. Lahcène Noureddine, Mustapha Noureddine, Ahmed Hafaifa, Abdellah Kouzou. DWT-PSD extraction feature for defects diagnosis of small wind generator. Diagnostyka;2019;20(3):45-52. https://doi.org/10.29354/diag/110458

23. Odgaard Peter Fogh, Jakob Stoustrup. Fault tolerant wind speed estimator used in wind turbine controllers. IFAC papers 2012, August 29-31. National Autonomous University of Mexico, Mexico City,https://doi.org/10.3182/20120829-3-MX2028.00009

24. Philip Cross, Xiandong Ma. Model-based and fuzzy logic approaches to condition monitoring of operational wind turbines. International Journal of Automation and Computing 2015; 12: 25-34. https://doi.org/10.1007/s11633-014-0863-9

25. Pongpak Lap-Arparat, Thananchai Leephakpreeda. Real-time maximized power generation of vertical axis wind turbines based on characteristic curves of power coefficients via fuzzy pulse width modulation load regulation. Energy 2019; 182: 975-987. https://doi.org/10.1016/j.energy.2019.06.098

26. Silvio Simani, Paolo Castaldi. Data-driven and adaptive control applications to a wind turbine benchmark model. Control Engineering Practice 2013;21(12):1678-1693.

https://doi.org/10.1016/j.conengprac.2013.08.009

27. Sy-Jye G, Jung-Hsing C, Chia-Hsin C. Fuzzy duration forecast model for wind turbine construction project subject to the impact of wind uncertainty. Automation in Construction 2017; 81: 401-410. https://doi.org/10.1016/j.autcon.2017.03.009

28. Viveiros C, Melício R, Igreja JM, Mendes VMF. Performance Assessment of a Wind Turbine Using Benchmark Model: Fuzzy Controllers and Discrete Adaptive LQG. Procedia Technology 2014; 17:487494. https://doi.org/10.1016/j.protcy.2014.10.257

29. Xinfang Zhang, Daping Xu, Yibing Liu. Intelligent control for large-scale variable speed variable pitch wind turbines. Journal of Control Theory and Applications 2004;2:305-311. https://doi.org/10.1007/s11768-004-0015-9

30. Zafer Civelek. Optimization of fuzzy logic (TakagiSugeno) blade pitch angle controller in wind turbines by genetic algorithm. Engineering Science and Technology, an International Journal 2020; 23(1): 19. https://doi.org/10.1016/j.jestch.2019.04.010

Received 2020-01-13

Accepted 2020-06-01

Available online 2020-06-08

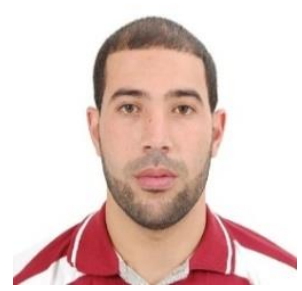

Mr Habib Chaouki Ben DJOUDI, was born in Setif, Algeria in 1992. He received the state of Master in automation and control of industrial systems in 2016 and Licence in electrical engineering and industrial computing in 2014 from Tiaret University and his obtained the diploma of Bachelor in Mathematics in 2011. Now he preparing his $\mathrm{PhD}$ degree on the study of stability problems at fault-tolerant control limits: Application to a wind energy system in the Applied Automation and Industrial Diagnostics Laboratory at Djelfa University.

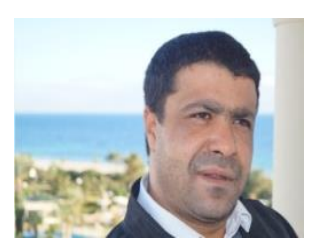

Professor Ahmed HAFAIFA was born in Algeria in 1974, $\mathrm{He}$ is a PhD and Full Professor in Industrial Process: Automation / Diagnosis and Reliability Engineering at the Science and Technology Faculty of the University of Djelfa, Algeria, where He is actually the named permanent Dean for the Science and Technology Faculty in April 2018 until now, after serving as the leader of Science and Technology Filed for five years since October 2014.

Currently $\mathrm{He}$ is the Director of the Applied Automation and Industrial Diagnostic Laboratory of the University of Djelfa and the leader of the Gas Turbine Joint Research Team, where Hi is the founder of these research entities, where $\mathrm{Hi}$ is initiated and supported several international research projects in collaboration and innovation activities with the industrial sector. Professor Ahmed HAFAIFA is the supervisor of many PhD Students in Algeria and he is the coordinator of several industrial research projects within the applied automatic and reliability of industrial systems. His research area of interests includes the modelling and control in industrial systems, the diagnosis and new reliability engineering, fault detection and isolation in industrials process, intelligent system based on fuzzy logic and neural networks. He is acting as an expert in several national and internationals commissions and collaboration research activities. He has supervised several Master students and published many national and international conferences and journals papers.

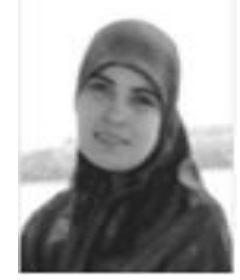

Dr Dalila DJOUDI was born in Djelfa, Algeria in 1978. She received the Diploma in electronic engineering from the Centre Universitaire de Djelfa, Djelfa, Algeria, in 2001, and the Ph.D. degree in robotics from the Université de Nantes, Nantes, France, in 2007. Since November 2007, she has been an Assistant Professor at the Universty of Djelfa. Her current research interests include control of walking robots and optimal motion for bipeds.

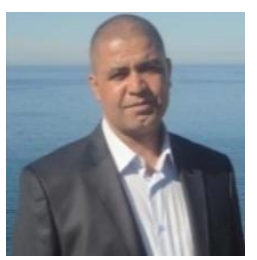

Dr. Guemana MOULOUD, $\mathrm{He}$ was born in Medea, Algeria in 1975. He received the state engineer degree of the national institute of hydrocarbons and chemistry INH on Mechanical Engineering from the University of Boumerdes, Algeria, in 1998. From May 1999 to January 2003.

$\mathrm{He}$ was associated researcher and associated lecturer. $\mathrm{He}$ received his Magister at the University of Boumerdes, Algeria in 2003. He received the Ph.D degree in Industrial Maintenance in 2012. Currently he is an associate Professor at the University of Medea, Algeria. $\mathrm{He}$ is the head of the reliability in industrial systems group at the Applied Automation and Industrial Diagnostic Laboratory. He is the author and co-author of many scientific papers and research projects. His research interests include industrial maintenance, reliability system, dynamical systems, and diagnostic and reliability optimization. 